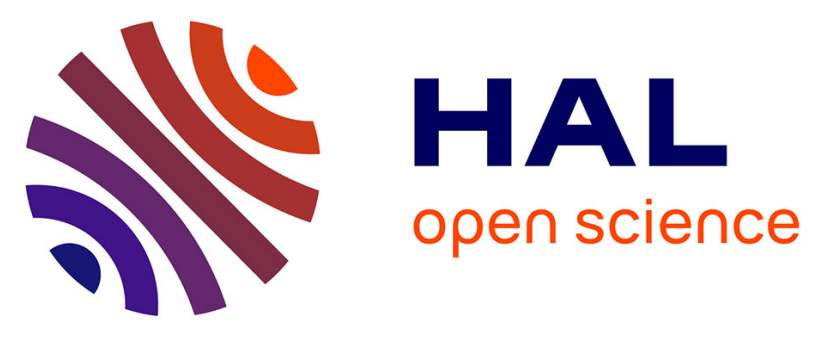

\title{
TLR agonist mediated suppression of allergic responses is associated with increased innate inflammation in the airways
}

Matthias J. Düchs, Christian Hahn, Ewald Benediktus, Melanie Werner-Klein, Armin Braun, Hans Gerd Hoymann, Florian Gantner, Klaus J. Erb

\section{To cite this version:}

Matthias J. Düchs, Christian Hahn, Ewald Benediktus, Melanie Werner-Klein, Armin Braun, et al.. TLR agonist mediated suppression of allergic responses is associated with increased innate inflammation in the airways. Pulmonary Pharmacology \& Therapeutics, 2011, 24 (2), pp.203. 10.1016/j.pupt.2010.12.009 . hal-00724891

\section{HAL Id: hal-00724891 \\ https://hal.science/hal-00724891}

Submitted on 23 Aug 2012

HAL is a multi-disciplinary open access archive for the deposit and dissemination of scientific research documents, whether they are published or not. The documents may come from teaching and research institutions in France or abroad, or from public or private research centers.
L'archive ouverte pluridisciplinaire HAL, est destinée au dépôt et à la diffusion de documents scientifiques de niveau recherche, publiés ou non, émanant des établissements d'enseignement et de recherche français ou étrangers, des laboratoires publics ou privés. 


\section{Accepted Manuscript}

Title: TLR agonist mediated suppression of allergic responses is associated with increased innate inflammation in the airways

Authors: Matthias J. Düchs, Christian Hahn, Ewald Benediktus, Melanie WernerKlein, Armin Braun, Hans Gerd Hoymann, Florian Gantner, Klaus J. Erb

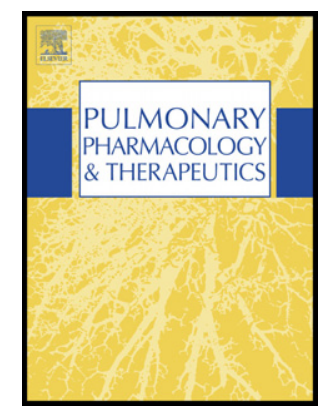

PII:

S1094-5539(10)00161-6

DOI:

10.1016/j.pupt.2010.12.009

Reference: YPUPT 1067

To appear in: Pulmonary Pharmacology \& Therapeutics

Received Date: 3 August 2010

Revised Date: 30 November 2010

Accepted Date: 23 December 2010

Please cite this article as: Düchs MJ, Hahn C, Benediktus E, Werner-Klein M, Braun A, Hoymann HG, Gantner F, Erb KJ. TLR agonist mediated suppression of allergic responses is associated with increased innate inflammation in the airways, Pulmonary Pharmacology \& Therapeutics (2010), doi: 10.1016/ j.pupt.2010.12.009

This is a PDF file of an unedited manuscript that has been accepted for publication. As a service to our customers we are providing this early version of the manuscript. The manuscript will undergo copyediting, typesetting, and review of the resulting proof before it is published in its final form. Please note that during the production process errors may be discovered which could affect the content, and all legal disclaimers that apply to the journal pertain. 
1 TLR agonist mediated suppression of allergic responses is associated with

2 increased innate inflammation in the airways

4 Matthias J. Düchs ${ }^{1}$, Christian Hahn ${ }^{1}$, Ewald Benediktus ${ }^{1,2}$, Melanie Werner-Klein ${ }^{1,3}$, Armin

5 Braun $^{4}$, Hans Gerd Hoymann ${ }^{4}$, Florian Gantner ${ }^{1}$ and Klaus J. Erb ${ }^{1}$

$6 \quad{ }^{1}$ Pulmonary Diseases Research, Boehringer Ingelheim Pharma GmbH \& Co. KG; Biberach

7 a.d. Riss, Germany; ${ }^{2}$ present address Nycomed GmbH, Institute of Pharmacology and

8 Preclinical Drug Safety, Barsbuettel, Germany; ${ }^{3}$ present address Universität Regensburg,

9 Germany; ${ }^{4}$ Fraunhofer Institut für Toxikologie und Experimentelle Medizin (ITEM),

10 Hannover, Germany

12 Correspondence and requests for reprints should be addressed to Prof. Dr. Klaus Erb, Ph.D.,

13 Pulmonary Diseases Research, Boehringer-Ingelheim Pharma GmbH \& Co. KG, H91-02-01,

14 Birkendorferstr. 65, D-88397 Biberach a.d. Riss, Germany. E-mail: klaus.erb@bc.boehringer-

15 ingelheim.com

16

17

18 


\section{ABSTRACT}

Toll-like receptor (TLR) mediated signalling induces pro-inflammatory responses and can both suppress and exacerbate allergic responses in the airways. The aim of our study was to directly compare the efficacy of different TLR agonists in inhibiting or exacerbating the development of Th2-mediated responses in the airways and investigate if the suppressive effects were associated with increased pro-inflammatory responses. Mice were immunized on day 0,14 and 21 by intraperitoneal injection of ovalbumin/alum and exposed to ovalbumin aerosol on day 26 and 27. TLR2-, TLR3-, TLR4-, TLR7- and TLR9 agonists (0.001, 0.01, 0.1 , or $1 \mathrm{mg} / \mathrm{kg}$ ) were administered intratracheally $1 \mathrm{~h}$ before each allergen exposure. Both the TLR7- and TLR9 agonists dose dependently reduced airway eosinophilia, while the TLR3 agonist only reduced airway eosinophilia at a dose of $1.0 \mathrm{mg} / \mathrm{kg}$. The TLR2- and TLR4 agonists potentiated eosinophilia. All TLR agonists enhanced neutrophil numbers at doses as low as $0.01 \mathrm{mg} / \mathrm{kg}$, in particular TLR2- and TLR4 agonists. TLR7- and TLR9 agonists also significantly reduced IL-4 and IL-5 levels and all TLR agonists, with the exception of TLR7, enhanced the amount IL-1B, IL-6, and TNF- $\alpha$ detected in the whole lung lavage. Only application of TLR9 agonist induced detectable levels of IL-10 in the lung. Suppressive effects of the TLR agonists were not dependent upon IFN- $\gamma$ and IL-10 or associated with increased numbers of Foxp $3^{+} \mathrm{CD} 4^{+} \mathrm{Tr}$ cells in the lavage fluid. Airway resistance was reduced significantly only when TLR7 agonist was administered. When applied therapeutically 2 days after allergen exposure, all TLR agonists, except TLR2, similarly reduced airway eosinophilia and IL-4 levels. Taken together our results show that TLR7 agonists had the strongest antiasthmatic effects with the lowest pro-inflammatory potential, suggesting that activating TLR7 may have the greatest potential to treat allergic disorders in humans. 
1 Keywords: mouse; asthma; allergy; eosinophils; neutrophils; TLR-agonists; innate-

2 inflammation

\section{Introduction}

Allergic asthma is characterized by the generation of allergen-specific $\mathrm{CD} 4^{+} \mathrm{T}$-helper type 2 (Th2) cells secreting IL-4, IL-5, IL-9, and IL-13 leading to chronic airway inflammation, goblet cell metaplasia, airway hyper-reactivity (AHR) and, in its severest form, tissue remodeling. Currently it is not entirely clear why one person develops asthma and another does not although both are exposed to allergens to the same degree. Genetic and environmental factors clearly have an impact [1,2]. In particular a lack of infections or the lack of exposure to certain commensals during early childhood have been hypothesized to be one, if not the major reason for the steady increase in asthma prevalence observed in both developed and recently developing countries [3-5].

Epidemiological findings and animal experiments support this view, and several studies have tried to identify factors which mediate the observed anti- or pro-asthmatic effects. The most prominent factors identified are Toll-like receptors (TLR). Currently 10 TLRs have been described in humans and 13 in other mammals. They belong to the family of pathogen recognition receptors (PRRs) and are expressed on a variety of cells. They bind to specific molecules (e.g., DNA, RNA, lipopolysaccharides (LPS), lipoteichonic acids (LTA), and others) produced by the pathogen and by commensals. TLR1, TLR2, TLR4, TLR5, TLR6, TLR10 and TLR11 are expressed on the cell surface, whereas TLR3, TLR7, TLR8 and TLR9 are expressed within the cells [6].

Animal studies have shown that the application of certain TLR-agonists can suppress the development of asthma and allergic responses [7-25]. The most widely studied TLR agonists are agonists of TLR2, TLR3, TLR4, TLR7, and TLR9. However, there are also 
1 studies showing that TLR agonists, in particular endotoxins, promote the development of

2 asthma and that this effect is dependent on the dose administered [26-31].

The aim of our current study was to directly compare the effect of different TLR

4 agonists (TLR2: lipoteichonic acid; TLR3: Poly(I:C); TLR4: lipopolysaccharide; TLR7:

5 resiquimod; TLR9: CpG-oligodeoxynucleotides) on the development of asthmatic responses

6 in murine models of asthma. The most important question we wanted to answer was, which

7 TLR-agonist is most efficacious in reducing allergic responses at a dose where no or very

8 little innate inflammation is induced. We found that the different TLR agonists tested have

9 different suppressive effects on the development of Th2-responses and different

10 proinflammatory properties in the airways of mice and these depend on the dose and in which

11 setting they were used. Reduction of Th2 responses, with the exception of using a TLR7

12 agonist, was always associated with increased proinflammation. 
1

2

3

4

\section{Materials and methods}

\section{$2.1 \quad$ TLR agonists}

For activation of murine TLR2, TLR3, TLR4, TLR7 and TLR9 the respective agonists were used; lipoteichonic acid from Staphylococcus aureus; LTA-SA, synthetic analog of double stranded RNA; Poly(I:C), lipopolysaccharide from E.coli K12; LPS-EK, small synthetic antiviral imidazoquinoline compound; R-848 and synthetic oligodeoxynucleotides containing unmethylated CpG dinucleotides; ODN1826. All TLR-agonist were purchased from InvivoGen, San Diego, USA.

\section{$2.2 \quad$ Mice}

Female C57B1/6, IL10-/- deficient (C57B1/6 background), and BALB/c mice were purchased from Charles River (Sulzfeld, Germany). At the onset of the experiments, animals were between 8 and 12 weeks of age and were kept in a pathogen-free animal facility. The mice had free access to food and water. Care and use of experimental animals conformed to the 'Guide for the Care and Use of Laboratory animals' published by the National Institute of Health (NIH publication 85-23, revised 1985), and the study was approved by the local governing authority.

\subsection{Treatment protocols}

C57Bl/6, IL10-/- deficient (C57B1/6 background) and BALB/c mice were sensitized intraperitoneal (i.p.) with a mixture of $20 \mu \mathrm{g}$ ovalbumin (Serva, Heidelberg, Germany) solved in $100 \mu \mathrm{l}$ phosphate buffered saline (PBS, Biowhittaker, Lonza, Verviers, Belgium) and adsorbed to $100 \mu \mathrm{l} \mathrm{Al}(\mathrm{OH})_{3}$ (Alum, Pierce, Rockford, USA). The total volume of $200 \mu \mathrm{l}$ was administered to animals on day 1, 14 and 21. Mice were exposed to $1 \%$ ovalbumin or PBS aerosol on two consecutive days (day 26 and day 27) for $20 \mathrm{~min}$. In the protective models 
$10.001,0.01,0.1$, and $1.0 \mathrm{mg} / \mathrm{kg}$ of TLR2-, TLR3-, TLR4-, TLR7- or TLR9 agonists

2 (InvivoGen, San Diego, USA) per mouse was solved in $50 \mu \mathrm{l}$ PBS and administered

3 intratracheal (i.tr.) $1 \mathrm{~h}$ before each ovalbumin exposure (Fig. 1A) or $1 \mathrm{mg} / \mathrm{kg} 4$ days prior to

4 allergen exposure (Fig. 1B). In the therapeutic model $1 \mathrm{mg} / \mathrm{kg}$ of respective TLR agonist was

5 administered intratracheal on day 29 followed by an additional ovalbumin exposure on day 33

6 (Fig. 1C). Mice were sacrificed $24 \mathrm{~h}$ after the last ovalbumin exposure. Vehicle controls were

7 sensitized intraperitoneal with PBS and Alum, and were exposed to PBS aerosol. The

8 ovalbumin and vehicle controls all received a sham intratracheal application of $50 \mu 1$ PBS at

9 the same point of time the other groups received TLR agonists.

112.4 Treatment of Mice with anti-IL-10 receptor and anti-IFN $\gamma$ neutralizing antibodies

Anti-IL-10 receptor ( $\alpha-$ IL-10R) monoclonal Antibodies (mAbs) (1B1.2) and anti-

IFN $\gamma(\alpha-I F N \gamma)$ mAbs (XMG1) were generously provided by Prof. Dr. Edgar Schmitt (Mainz,

Germany). BALB/c mice were treated with anti-IL-10R or anti-IFN $\gamma$ mAbs $(250 \mu \mathrm{g} / \mathrm{mouse}$ insertion of a cannula into the trachea lungs were flushed with $0.8 \mathrm{ml}$ of buffer twice.

intraperitoneal). As controls, mice were treated with $250 \mu \mathrm{g} / \mathrm{mouse}$ of purified rat serum IgG (control IgG) mAbs (Sigma, Steinheim, Germany). All antibodies were administered on day 25, 1 day prior to TLR application and ovalbumin exposure.

\subsection{Whole lung lavage}

Whole lung lavage was performed at the indicated time-points, $24 \mathrm{~h}$ after the last ovalbumin exposure. Lavage buffer consisted of $1 \%$ bovine serum albumin (Sigma-Aldrich, Steinheim, Germany), 0,0012 \% 0,5M EDTA (Promega, Madison, USA) and proteinase inhibitor (Complete Protease Inhibitor Cocktail Tablets, Roche Diagnostics GmbH, Mannheim, Germany) in Hank's salt solution (Biochrom AG, Berlin, Germany) After 


\subsection{Detection of Cytokines by ELISA and multiplex technology}

2

In the protective model (Fig. 1A) amount of cytokines and chemokines in the whole lung lavage fluid were determined using the 96 well plate mouse cytokine/chemokine premixed multiplex lincoplex KIT assay (LINCO, St. Charles, USA) according to the manufactures instructions. In brief, fluorescently labeled microspheres coated with cytokinespecific capture mAbs were incubated overnight at $2-8^{\circ} \mathrm{C}$ with $25 \mu \mathrm{l}$ of whole lung lavage. After two washing steps, biotinylated detection mAbs were added and incubated for $60 \mathrm{~min}$ at room temperature, followed by 30 min of incubation with streptavidin-phycoerythrin. After three washing steps sheath fluid was added and the plates were analyzed using a Bio-Plex reader (Bio-Rad, München, Germany). Standard curves and concentrations were calculated with BioPlex Manager 3.0 software. In preventive and therapeutic models amounts of IL-4 and IL-5 in the whole lung lavage were measured by standard ELISA, using BD Biosciences mouse IL-4 and BD Biosciences mouse IL-5 ELISA sets (BD Biosciences, San Diego, USA) according to the manufactures instructions for detection.

\subsection{Histological analysis}

Lungs were prepared $24 \mathrm{~h}$ after the last TLR ovalbumin exposure. Lungs were fixed in $4 \%$ phosphate-buffered formalin for $24 \mathrm{~h}$ and embedded in paraffin wax. Sections $(2-3 \mu \mathrm{m})$ were cut and stained using standard histological protocols with haematoxylin and eosin (H\&E) reagent (Merck, Darmstadt, Germany). The stained sections were visualized by light microscopy.

\subsection{Measurement of airway hyperreactivity}

For invasive measurements of resistance mice were anesthetized with $1.8 \%$ halothane/40 \% oxygen by inhalation after pre-medication with $77 \mathrm{mg} / \mathrm{kg}$ propofol given intraperitoneal on day $28,24 \pm 2 \mathrm{~h}$ after the final ovalbumin exposure. AHR was then assessed 
1 after challenge with aerosolized methacholine chloride (MCh; Sigma, Deisenhofen, Germany)

2 in intubated, spontaneously breathing mice as described previously [32,33]. Briefly, mice

3 were placed in supine position in a body plethysmography (type 871, HSE-Harvard

4 Apparatus, March-Hugstetten, Germany) and pulmonary resistance (RL) was calculated from

5 the measured signals of transpulmonary pressure and tidal respiratory flow and continuously

6 recorded using commercial software (HEM 3.5, Notocord, Croissy, France). After recording

7 of baseline values, the mice were exposed to aerosolized MCh (from $5 \%$ solution) in dose steps of $0.063,0.125,0.25,0.5,1,2$ and $4 \mu \mathrm{g}$ under continuation of lung function registration.

9 Dried aerosols were generated by a computer-controlled, jet-driven aerosol generator system (particle size $2.8 \mu \mathrm{m}$ MMAD; Bronchy III, Fraunhofer ITEM, licensed by Buxco, Troy, NY, USA). Aerosol concentrations were determined by a gravimetrically calibrated photometer. The total dose inhaled via the orotracheal tube in $\mu \mathrm{g}$ was calculated and controlled by a computerized dose-control system (Fraunhofer ITEM) based on the continuously measured respiratory minute volume and aerosol concentration [34]. From dose-effect plots (delta\% RL vs. MCh dose) the effective inhalation dose in $\mu \mathrm{g}$ MCh required to produce a $150 \%$ increase in RL was evaluated for each animal (ED150 RL). was used for red blood cell lysis and cells were washed and further processed in PBS supplemented with 0,5\% BSA. The cell surface was stained with PerCP-Cy5.5 conjugated anti-mouse CD4 antibody (BD Biosciences, Heidelberg, Germany). For detection of intracellular FOXP3 antigen, the Mouse/Rat FOXP3 staining set (eBioscience, San Diego, USA) was used according to the manufactures instructions. Fluorescence was analyzed on a 
1 by BD FACS DIVA Software 5.0. Gates were set on lymphocytes based on forward and side

2 scatter properties, quadrants were defined using isotype controls.

\section{$4 \quad 2.10 \quad$ Statistical analysis}

Statistical differences between different groups were evaluated by One-way ANOVA or unpaired t-test. One-way analysis of variance together with the Dunett's post test was used for comparisons of all groups vs. the ovalbumin group. In airway hyperreactivity measurement statistical differences of area under the curve (AUC) between vehicle control group and ovalbumin treated animals were evaluated with unpaired t-test. The results are expressed as mean \pm standard error of means (SEM). A $P$-value of $<0.05$ was considered

\section{1 significant.}

\section{Results}

3.1 Effects of TLR agonists in a preventive setting on the development of allergic inflammation in the lungs

17

The pro-inflammatory and anti-asthmatic effects of five different TLR agonists were tested in a preventive model for allergic asthma in mice. For this purpose, doses of 0.001 , 0.01, 0.1 and $1.0 \mathrm{mg} / \mathrm{kg}$ of TLR2-, TLR3-, TLR4-, TLR7- and TLR9 agonists were given intratracheal one hour before each allergen exposure (Fig. 1A). We then analyzed which TLR agonists induced the strongest influx of macrophages and neutrophils and which had the strongest inhibitory effect on the development of airway-eosinophilia. In our model a very strong eosinophilia is induced. However, a weak neutrophilia is also present. How the neutrophilia impacts on lung pathology is not known. Based on publications showing that the presence of neutrophils correlates with impaired lung function, we suggest that the neutrophils 
1 together with the eosinophils may contribute to the increased AHR after MCH challenge in

2 the OVA treated and challenged mice. Figure 2 shows that all agonists, with the exception of

3 TLR7 agonist, dose dependently increased the amounts of total macrophages found in the

4 whole lung lavage. A similar effect was seen on the recruitment of neutrophils into the lung.

5 Interestingly, administration of TLR7 agonist also induced a very weak neutrophilia, at a dose

6 of $0.1 \mathrm{mg} / \mathrm{kg}$. Surprisingly, compared to other published reports $[12 ; 17 ; 24 ; 25]$, we found that

7 only TLR3-, TLR7-, and TLR9 agonists suppressed the development of allergen induced airway eosinophilia. In contrast, we detected a significant increase in the recruitment of eosinophils when lower doses of either TLR2- or TLR4 agonists were used. Histological analysis confirmed the overall lower inflammation detected in the TLR3-, TLR7- and TLR9 agonist treated mice in comparison to the ovalbumin controls and TLR2- and TLR4 agonist treated animals which showed the strongest inflammation (Fig. 3).

All tested agonists, again with the exception of TLR7, induced the production of the pro-inflammatory cytokines and chemokines IL-6, IL-1ß, TNF- $\alpha$ and reduced the levels of IL-4 and IL-5 in the whole lung lavage (Fig. 4). Most of the observed effects were dose dependent. Interestingly, we found that TLR9 agonist was the only agonist inducing the production of IL-10. IL-13 was also reduced in the mice treated with agonists TLR9, TLR7, TLR4 and TLR2 and no difference in the amount of IFN- $\gamma$ was found in any of the ovalbumin treated groups (data not shown). IL-12 and IFN- $\alpha$ and $-\beta$ could not be detected in any of the whole lung lavage samples. When the TLR agonists were administered alone and the animals were not treated with ovalbumin enhanced IL-6, IL-1 $\beta$, and TNF- $\alpha$ levels were also detected in the whole lung lavage (data not shown).

We also analyzed which of the TLR agonists had suppressive effects on the development of AHR. Figure 5 shows that only the TLR7 agonist significantly reduced AHR. 
1 different protocols used. For this reason we also administered the different TLR agonist

2 intratracheal at the highest dose, once, 4 days before the allergen exposure (Fig. 1B). We

3 found that in this experimental setting all of the TLR agonists inhibited the development of

4 airway eosinophilia. No significant increase in neutrophil numbers was detected and TLR4

5 agonist was the only TLR agonist that induced a significant increase in macrophage numbers

6 at this time point. The lack of neutrophilia was somewhat surprising, since we observed a

7 strong neutrophilia in the airways, when the TLR agonists were administered directly before

8 the allergen challenge (Figure 2.). The most likely explanation for this finding is that in all

9 cases a neutrophilia is induced, however, at the later time-point no longer detectable.

10 Supporting this view are kinetic studies showing that the maximum neutrophilia in the lung is

11 observed $24 \mathrm{~h}$ after TLR application and no or few neutrophils are present 5 days after the

12 application (data not shown). TLR2-, TLR3-, and TLR4 agonists also reduced IL-4 and IL-5

13 levels whereas TLR9 agonists only reduced IL-4 levels in the whole lung lavage (Figure 6B).

14 Interestingly, the TLR-4 and TLR9 agonist treated mice also showed reduced AHR (Fig. 6C).

3.2 Suppressive effects of TLR agonists in a preventive setting were not dependent on IL-

10, IFN- - or enhanced numbers of Tr cells in the airways

Previous studies suggest that the suppressive effects of different TLR agonists on the development of allergic responses may be associated with the production of IFN- $\gamma$, IL-10 or activation of FoxP3+ $\operatorname{Tr}$ cells $[6 ; 11 ; 13 ; 14 ; 21 ; 34]$. For this reason, we repeated the experiments shown in Figure 1A in IL-10 deficient mice on a C57B1/6 background using the three agonists, which showed a significant reduction in Th2 responses in the lung. Figure 7A shows that the suppressive effects of the three tested TLR agonists were similar in both the 25 control and IL-10 deficient mice. Furthermore, treating ovalbumin immunised/exposed and TLR agonist treated BALB/c mice with anti-IFN- $\gamma$ or anti-IL-10 receptor neutralizing 
1 antibodies showed that the suppressive effects appeared not to be dependent upon either IFN-

$2 \gamma$ or IL-10 (Fig. 7B). We also analyzed if increased numbers of Foxp3 ${ }^{+}$Tr cells could be

3 found in the whole lung lavage of ovalbumin and TLR agonist treated mice. Figure 8 shows

4 that the suppressive effects of TLR3-, TLR7- and TLR9 agonist were not associated with

5 increased numbers of $\mathrm{FoxP}^{+} \mathrm{CD}^{+} \mathrm{T}$ cells in the whole lung lavage. Interestingly, both

6 TLR2- and TLR4 agonists treated mice showed increased numbers of $\mathrm{Tr}$ cells in the whole

7 lung lavage, albeit without reducing the overall numbers of eosinophils. Surprisingly we

8 found strongly reduced numbers of FoxP $3^{+} \mathrm{CD} 4^{+}$and $\mathrm{CD} 4^{+} \mathrm{T}$ cells in the whole lung lavage of

$9 \quad$ TLR7 agonist treated mice.

$113.3 \quad$ TLR agonist mediated suppression of allergen-induced eosinophilia in a therapeutic 12 setting

The experiments above clearly show that some but not all of the tested TLR-agonists reduced the development of allergen-induced Th2-responses in the lung when administered

before allergen exposure. In this experimental preventive setting no lung inflammation has occurred prior to the treatment with the TLR agonists (data not shown). For this reason we also analyzed the effects of the different TLR agonists in a therapeutic setting where the TLR agonists were administered intratracheal 2 days after the second ovalbumin exposure (day 30) followed by a final allergen-exposure on day 33 (Fig. 1C). For these experiments we used the dose which had the greatest suppressive effect in the protective model. Figure 9A shows that all the TLR agonists with the exception of the TLR2 agonist significantly reduced the development of airway eosinophilia. No increase in neutrophil numbers was observed in any of the treated mice. However, TLR4 agonist treated mice showed a significant increase in total macrophage numbers. All TLR agonists reduced IL-4 levels in the whole lung lavage. IL-5 levels were also significantly reduced (with the exception of the TLR4 agonist treated mice). 
2

\section{Discussion}

The aim of this study was to determine the efficacy of different TLR agonists in suppressing the development of Th2-mediated responses in the airways and to investigate if the suppressive effects were associated with increased pro-inflammatory responses. We found that when the different agonists were administered intratracheally $1 \mathrm{~h}$ before allergen exposure (preventive setting) TLR9-, TLR7-, and TLR3 agonists dose dependently suppressed the development of allergen induced airway eosinophilia, and IL-4 and IL-5 levels detected in the whole lung lavage. These findings are in unison with previously published reports $[10 ; 13 ; 14 ; 22]$. With the exception of TLR7 agonist all the agonists, dose dependently increased the amounts of total macrophages, neutrophils and pro-inflammatory cytokines found in the whole lung lavage. The stronger the inflammatory response induced by TLR9and TLR3 agonist, the stronger the suppressive effect on the development of allergen-induced Th2-mediated responses. TLR7 agonist showed only a weak induction of a pro-inflammatory response but was the only agonist found to significantly reduce AHR. In contrast to other published reports [12;17;24;25] we found that application of TLR4- or TLR2 agonist did not suppress the development of allergen induced Th2-responses in the lung or AHR. However, this may be due to different protocols used. Supporting this view was our finding that when we administered the different TLR agonist intratracheal at the highest dose once 4 days before the allergen exposure, all of the TLR agonists inhibited the development of airway eosinophilia. This clearly suggests that the effects of TLR4- and TLR2 agonist depend on the time point of application. Supporting this view was our finding that under these conditions the TLR4- and now also the TLR9 agonists reduced AHR, an effect not seen when they were administered directly before allergen challenge. Surprisingly, the TLR7 agonist which showed a protective effect on AHR given directly before allergen challenge, no longer had an effect 
1 under these conditions. This shows that the protective effects of different TLR agonists on

2 AHR strongly depend on the time they were administered in respect to allergen challenge.

It appears that the kinetics of the induction of protective factors were different between the TLR agonists. We detected increased amounts of FoxP3+ cells in TLR2- and TLR4 agonist treated lungs. Possibly these cells need to be activated longer before allergen challenge to have a suppressive effect on the Th2 responses in the lung. A further surprising result was, that TLR agonist induced eosinophil reduction did not always correlate with a reduction in IL-4 and IL-5 (TLR7- and TLR9 agonist) levels in the lavage fluid. Why the effects are so different between the TLR agonists used, although they signal through very similar signal transduction pathways leading to similar proinflammatory responses [6;23], is not clear. We hypothesize that the outcome in respect to the strength and quality of the innate response and the anti-asthmatic effects strongly depend on the expression pattern of the different TLRs on a particular cell and the amount of this cell type present in the lung. reduction of allergic responses in the lung? Based on previous publications the following mediators may play a role IL-10, IL-12, IFN- $\alpha$ and $-\beta$, or IFN- $\gamma$. Experiments performed in IL-10 deficient mice or mice treated with anti-IL-10 receptor or IFN- $\gamma$ neutralizing antibodies suggest that IL-10 or IFN- $\gamma$ were not responsible for the observed inhibitory effects. This was somewhat surprising for the TLR9 agonist, since we found a strong induction of IL-10 after the intra tracheal application. It is also possible that TLR9- and TLR3 agonist exert their suppressive effect through both IL-10 and IL-12, a mechanism recently published for these two agonists [14]. Type 1 IFNs are strong inhibitors of allergic responses [6;23;34;35], however, we could not detect IFN- $\alpha$ or $-\beta$ in the whole lung lavage suggesting that these may not be responsible for the suppression of the allergic response. We cannot rule out the possibility that they were induced in too small an amount to be detected by ELISA. The 
1 induction of regulatory $\mathrm{T}$ cells ( $\mathrm{Tr}$ ) has also been hypothesized in TLR agonist mediated

2 suppression of allergic disorders $[23 ; 34 ; 35]$. However, in our experiments $\mathrm{CD}^{+} \mathrm{FoxP} 3^{+} \mathrm{T}$ cell

3 numbers in the whole lung lavage did not increase in the groups which showed reduced

4 allergic responses. Interestingly, Tr numbers were increased in the TLR4- and TLR2 agonist

5 treated mice, which showed no reduced allergic response when administered directly before

6 the allergen-exposure.

Currently, we cannot answer the question by which mechanism the different TLR agonists mediate their suppressive effects, however TLR7 agonists may have a different mode of action than the TLR9- and TLR3 agonists. We found, that the TLR7 agonist treated mice had a strong reduction in total $\mathrm{CD} 4^{+} \mathrm{T}$ cell numbers in the whole lung lavage. This suggests that TLR7 agonist treatment may lead to a loss or lack of recruitment of CD4 ${ }^{+}$cells into the 12 lung, thus explaining the reduced Th2-responses detected in the airways. Supporting this view 13 is the previously published report that the TLR7 agonist R-848, which we also used for our 14 study, leads to a lymphopenia [36]. This would also possibly explain why the weak 15 proinflammation detected in the TLR7-agonist treated mice was associated with suppressed 16 Th2-responses in our model. If this is a general effect of a TLR7 agonist or an off-target effect 17 of R-848 needs to be determined.

When treating patients with atopic asthma, with the exception of seasonal asthma, all patients will have ongoing Th2 type inflammation in the airways [1]. In respect to possible future use in humans, we also analyzed the effects of the different TLR agonists in a

21 therapeutic setting. In this setting the TLR agonists were administered after the allergic 22 inflammation in the lung has already occurred. We found that all TLR agonists with the 23 exception of TLR2 significantly reduced the development of airway eosinophilia and IL-4 24 levels in the whole lung lavage. No increase in numbers of neutrophils was observed. This 
1 suggests that TLR agonists may also be used to treat patients with established allergic

2 inflammation in the airways.

Previous reports suggest that infections and the application of TLR agonists can also exacerbate allergic responses, in particular TLR4- and TLR2 agonist LPS and LTA-SA [2629]. We also found some evidence that TLR agonists increased the allergic Th2 response. At low doses both TLR4- and TLR2 agonist significantly increased allergen-induced recruitment of eosinophils into the airways when administered directly into the lung before allergen exposure. This supports the hypothesis, that some TLR agonist can also increase allergic responses, in particular, when low doses are administered. This also needs to be taken into account when patients are to be treated.

In conclusion, we found that the TLR2-, TLR3-, TLR4-, TLR7-, and TLR9 agonists have different suppressive effects on the development of Th2-mediated responses in the airways. These depend on the dose and at which point in time, in respect to allergen exposure, they were given e.g. one day or 4 days before allergen challenge or in a therapeutic setting after allergen challenge. All the tested agonists induced airway neutrophilia and with the exception of TLR7 agonists increased the amounts of pro-inflammatory cytokines in the airways, albeit to different degrees, when directly administered into the lung. This raises the question if any of the tested TLR agonists are safe for human use when repeatedly administered directly into the lung. In particular TLR2- and TLR4 agonists which showed a severe inflammation in the lungs as detected by histology and the presence of large numbers 21 of neutrophils in the lung lavage. However, the TLR7 agonists showed only a weak pro 22 inflammatory potential and a high anti-allergic effect, suggesting that a TLR7 agonist may be used in humans to treat asthma. Nevertheless, it is possible, that small pro-inflammatory responses may be tolerable in patients suffering from allergic asthma, thereby possibly also 
1 the use of novel therapeutic agents that might cause an increase in neutrophils in a population

2 of patients with already altered airway function.

3

4

5

6

7

8 


\section{REFERENCES}

1. Barnes PJ. Immunology of asthma and chronic obstructive pulmonary disease. Nat Rev Immunol 2008; 8:183-92.

2. Fabbri L, Peters SP, Pavord I, Wenzel SE, Lazarus SC, MacNee W, Lemaire F, Abraham E. Allergic Rhinitis, Asthma, Airway Biology, and Chronic Obstructive Pulmonary Disease in AJRCCM in 2004. Am J Respir Crit Care Med 2005; 171:686-98.

3. Cookson WO, Moffatt MF. Asthma: an epidemic in the absence of infection? Science 1997; 275:41-2.

4. Erb KJ. Atopic disorders: a default pathway in the absence of infection? Immunol Today 1999; 20:317-22.

5. Kamradt T, Goggel R, Erb KJ. Induction, exacerbation and inhibition of allergic and autoimmune diseases by infection. Trends Immunol 2005; 26:260-7.

6. Kaisho T, Akira S. Toll-like receptor function and signaling. Journal of Allergy and Clinical Immunology 2006; 117:979-87.

7. Camateros P, Tamaoka M, Hassan M, Marino R, Moisan J, Marion D, Guiot MC, Martin JG, Radzioch D. Chronic asthma-induced airway remodeling is prevented by toll-like receptor-7/8 ligand S28463. Am J Respir Crit Care Med 2007; 175:1241-9.

8. Ashino S, Wakita D, Zhang Y, Chamoto K, Kitamura H, Nishimura T. CpG-ODN inhibits airway inflammation at effector phase through down-regulation of antigenspecific Th2-cell migration into lung. Int Immunol 2008; 20:259-66.

9. Kline JN, Krieg AM, Waldschmidt TJ, Ballas ZK, Jain V, Businga TR. CpG oligodeoxynucleotides do not require TH1 cytokines to prevent eosinophilic airway inflammation in a murine model of asthma. J Allergy Clin Immunol 1999; 104:1258-64.

10. Kline JN, Waldschmidt TJ, Businga TR, Lemish JE, Weinstock JV, Thorne PS, Krieg AM. Cutting Edge: Modulation of Airway Inflammation by $\mathrm{CpG}$ Oligodeoxynucleotides in a Murine Model of Asthma. J Immunol 1998; 160:2555-9.

11. Horner AA, Raz E. Do microbes influence the pathogenesis of allergic diseases? Building the case for Toll-like receptor ligands. Curr Opin Immunol 2003; 15:614-9.

12. Gerhold K, Blümchen K, Bock A, Seib C, Stock P, Kallinich T, Löhning M, Wahn U, Hamelmann E. Endotoxins prevent murine IgE production, TH2 immune responses, and development of airway eosinophilia but not airway hyperreactivity. Journal of Allergy and Clinical Immunology 2002; 110:110-6.

13. Wohlleben G, Erb KJ. Immune stimulatory strategies for the prevention and treatment of asthma. Curr Pharm Des 2006; 12:3281-92.

14. Sel S, Wegmann M, Sel S, Bauer S, Garn H, Alber G, Renz H. Immunomodulatory effects of viral TLR ligands on experimental asthma depend on the additive effects of IL-12 and IL-10. J Immunol 2007; 178:7805-13. 
15. Fanucchi MV, Schelegle ES, Baker GL, Evans MJ, McDonald RJ, Gershwin LJ, Raz E, Hyde DM, Plopper CG, Miller LA. Immunostimulatory oligonucleotides attenuate airways remodeling in allergic monkeys. Am J Respir Crit Care Med 2004; 170:1153-7.

16. Hessel EM, Chu M, Lizcano JO, Chang B, Herman N, Kell SA, Wills-Karp M, Coffman RL. Immunostimulatory oligonucleotides block allergic airway inflammation by inhibiting Th2 cell activation and IgE-mediated cytokine induction. J Exp Med 2005; 202:1563-73.

17. Akdis CA, Kussebi F, Pulendran B, Akdis M, Lauener RP, Schmidt-Weber CB, Klunker S, Isitmangil G, Hansjee N, Wynn TA, Dillon S, Erb P, Baschang G, Blaser K, Alkan SS. Inhibition of T helper 2-type responses, IgE production and eosinophilia by synthetic lipopeptides. Eur J Immunol 2003; 33:2717-26.

18. Banerjee B, Kelly KJ, Fink JN, Henderson JD, Jr., Bansal NK, Kurup VP. Modulation of airway inflammation by immunostimulatory $\mathrm{CpG}$ oligodeoxynucleotides in a murine model of allergic aspergillosis. Infect Immun 2004; 72:6087-94.

19. Piggott DA, Eisenbarth SC, Xu L, Constant SL, Huleatt JW, Herrick CA, Bottomly K. MyD88-dependent induction of allergic Th2 responses to intranasal antigen. J Clin Invest 2005; 115:459-67.

20. Kitagaki K, Businga TR, Kline JN. Oral administration of CpG -ODNs suppresses antigen-induced asthma in mice. Clin Exp Immunol 2006; 143:249-59.

21. Racila DM, Kline JN. Perspectives in asthma: molecular use of microbial products in asthma prevention and treatment. J Allergy Clin Immunol 2005; 116:1202-5.

22. Quarcoo D, Weixler S, Joachim RA, Stock P, Kallinich T, Ahrens B, Hamelmann E. Resiquimod, a new immune response modifier from the family of imidazoquinolinamines, inhibits allergen-induced Th2 responses, airway inflammation and airway hyper-reactivity in mice. Clin Exp Allergy 2004; 34:1314-20.

23. Yang IA, Fong KM, Holgate ST, Holloway JW. The role of Toll-like receptors and related receptors of the innate immune system in asthma. Curr Opin Allergy Clin Immunol 2006; 6:23-8.

24. Taylor RC, Richmond P, Upham JW. Toll-like receptor 2 ligands inhibit TH2 responses to mite allergen. J Allergy Clin Immunol 2006; 117:1148-54.

25. Velasco G, Campo M, Manrique OJ, Bellou A, He H, Arestides RS, Schaub B, Perkins DL, Finn PW. Toll-like receptor 4 or 2 agonists decrease allergic inflammation. Am J Respir Cell Mol Biol 2005; 32:218-24.

26. Lam D, Ng N, Lee S, Batzer G, Horner AA. Airway house dust extract exposures modify allergen-induced airway hypersensitivity responses by TLR4-dependent and independent pathways. J Immunol 2008; 181:2925-32.

27. Chisholm D, Libet L, Hayashi T, Horner AA. Airway peptidoglycan and immunostimulatory DNA exposures have divergent effects on the development of airway allergen hypersensitivities. J Allergy Clin Immunol 2004; 113:448-54. 
28. Redecke V, Hacker H, Datta SK, Fermin A, Pitha PM, Broide DH, Raz E. Cutting edge: activation of Toll-like receptor 2 induces a Th2 immune response and promotes experimental asthma. J Immunol 2004; 172:2739-43.

29. Dong L, Li H, Wang S, Li Y. Different doses of lipopolysaccharides regulate the lung inflammation of asthmatic mice via TLR4 pathway in alveolar macrophages. J Asthma 2009; 46:229-33.

30. Hammad H, Chieppa M, Perros F, Willart MA, Germain RN, Lambrecht BN. House dust mite allergen induces asthma via Toll-like receptor 4 triggering of airway structural cells. Nat Med 2009; 15:410-6.

31. Johnston SL, Martin RJ. Chlamydophila pneumoniae and Mycoplasma pneumoniae: A Role in Asthma Pathogenesis? Am J Respir Crit Care Med 2005; 172:1078-89.

32. Glaab, T., W. Mitzner, A. Braun, H. Ernst, R. Korolewitz, J. M. Hohlfeld, N. Krug, and H. G. Hoymann. Repetitive measurements of pulmonary mechanics to inhaled cholinergic challenge in spontaneously breathing mice. J Appl Physiol 2004; 97:11041111

33. Hoymann, H. G. New developments in lung function measurements in rodents. Experimental and Toxicologic Pathology 2006; 57:5-11.

34. Kline JN. Eat dirt: CpG DNA and immunomodulation of asthma. Proc Am Thorac Soc 2007; 4:283-8.

35. Liu G, Zhao Y. Toll-like receptors and immune regulation: their direct and indirect modulation on regulatory CD4+ CD25+ T cells. Immunology 2007; 122:149-56.

36. Gunzer M, Riemann H, Basoglu Y, Hillmer A, Weishaupt C, Balkow S, Benninghoff B, Ernst B, Steinert M, Scholzen T, Sunderkotter C, Grabbe S. Systemic administration of a TLR7 ligand leads to transient immune incompetence due to peripheral-blood leukocyte depletion. Blood 2005; 106:2424-32. 


\section{FIGURE LEGENDS}

Fig. 1: Treatment protocols used for TLR agonist administration. (A) Protective model with administration of TLR agonists on day 26 and 27, (B) protective administration of TLR agonists on day 22, and (C) therapeutic model with administration of TLR agonists on day 30.

Fig. 2: TLR agonists suppress allergen-induced eosinophilia and induce airway neutrophilia. (A) Total number of cells in whole lung lavage was determined $24 \mathrm{~h}$ after the last ovalbumin exposure. Data are presented as mean \pm SEM of 8 mice/group. ${ }^{*} \mathrm{p}<0.05$, $* * \mathrm{p}<0.01, * * * \mathrm{p}<0.001$, in comparison with the ovalbumin group.

Fig. 3: Histological analysis of the lungs from ovalbumin and TLR agonist treated

mice. (A) Lung tissues were obtained from naïve mice treated with the TLR agonists alone or (B) from ovalbumin sensitized and exposed mice treated with different TLR agonists as indicated in Figure 1 (A) (1.0 mg/kg of TLR2-, TLR3-, TLR4-, TLR7- and TLR9 agonist were used). Tissues were stained with haematoxylin and eosin, and examined by light microscopy. Scale bar $=100 \mu \mathrm{m}$. Shown are representative examples of 8 mice/group.

Fig. 4: TLR agonist treated mice show a reduction of Th2 cytokines and increase in pro-inflammatory cytokines and chemokines in the airways. Mice were sensitized and challenged with ovalbumin as indicated in material and methods (Fig. 1A). TLR agonists in dose of 1.0, 0.1, 0.01 and $0.001 \mathrm{mg} / \mathrm{kg}$ were administered on day 26 and 27 . The amount of the different mediators in the whole lung lavage were determined $24 \mathrm{~h}$ after the last ovalbumin exposure, as described in materials and methods ( $\boldsymbol{\square}=$ TLR2 agonist, $\square=$ TLR3 agonist, $\square=$ TLR4 agonist, $\square=$ TLR7 agonist, $\square=$ TLR9 agonist). Data are presented as mean \pm SEM of 8 mice/group. ${ }^{*} \mathrm{p}<0.05$, in comparison with the ovalbumin group. 
Fig. 5: TLR7 agonist reduces airway resistance after methacholine exposure.

2 For invasive measurement of resistance mice were first exposed to nebulised saline (PBS),

3 followed by increasing doses of methacholine. Columns represent the effective inhalational

4 dose of $\mathrm{MCh}$ in $\mu \mathrm{g}$ required to increase pulmonary resistance (RL) by $150 \%$ above baseline

5 (ED150 RL). Significant, complete inhibition of airway hyperresponsiveness was observed in

6 mice pre-treated with the TLR7 agonist. Data are presented as mean \pm SEM with 9-16

7 mice/group. $* * * \mathrm{p}<0.001$, in comparison to the ovalbumin group.

8

Fig. 6: Pre-treatment with TLR agonists inhibits influx of eosinophils, production of IL-4 and TLR4- and TLR9 agonist pre-treatment reduces airway resistance. BALB/c mice were sensitized with ovalbumin, treated with different TLR agonists and exposed to ovalbumin as indicated in material and methods (Fig. 1B). (A) Whole lung lavage was collected $24 \mathrm{~h}$ after the last ovalbumin exposure and the number of inflammatory cells and (B) levels of IL-4 and IL-5 in the whole lung lavage were determined. (C) Invasive measurement of airway resistance. Columns represent the effective inhalational dose of $\mathrm{MCh}$ in $\mu \mathrm{g}$ required to increase pulmonary resistance (RL) by $150 \%$ above baseline (ED150 RL). Significant inhibition of airway hyperresponsiveness was observed in mice pre-treated with TLR4- and TLR9 agonist. Data are presented as mean \pm SEM with 6-8 mice/group. ${ }^{*} \mathrm{p}<0.05$, $* * \mathrm{p}<0.01, * * * \mathrm{p}<0.001$ in comparison to the ovalbumin group.

Fig. 7: IL-10 and IFN- $\gamma$ mediated signaling is not necessary for TLR agonist mediated suppression of airway eosinophilia. (A) C57B1/6NCrl, C57B1/6NCrl IL10-/-, and (B) BALB/c mice were sensitized and exposed to ovalbumin and treated with different TLR agonists as indicated in material and methods (Fig. 1A). (B) On day $25 \mathrm{BALB} / \mathrm{c}$ mice received intra peritoneal injection of either anti-IL-10R or anti-IFN- $\gamma$ neutralizing antibodies. 
1 Number of cells in the whole lung lavage was determined $24 \mathrm{~h}$ after the last exposure. Data

2 are presented as mean \pm SEM of 8 mice/group. ${ }^{*} \mathrm{p}<0.05$, $* * \mathrm{p}<0.01, * * * \mathrm{p}<0.001$, in comparison

3 with the ovalbumin group.

4

Fig. 8: Detection of FOXP3+/CD4+ T-cells in the whole lung lavage from

ovalbumin and TLR agonist treated mice. Whole lung lavage cells were stained as described in materials and methods. (A) Shown are representative examples of whole lung lavage cells stained for CD4+ surface and FOXP3 intracellular expression. Total numbers of CD4+ and CD4+/FOXP3+ cells in the whole lung lavage (\% of ovalbumin control) are shown in (B) and (C), respectively. Data are presented as mean \pm SEM of 4 samples/group (whole lung lavage cells from 4 mice/group were pooled ( $\mathrm{n}=2 /$ group) from 2 separate experiments (total of $\mathrm{n}=4) . * \mathrm{p}<0.05, * * \mathrm{p}<0.01, * * * \mathrm{p}<0.001$, in comparison with the ovalbumin group.

Fig. 9: TLR agonists suppress the development of allergen-induced eosinophilia and IL-4 production in the airways in a therapeutic setting. BALB/c mice were sensitised, exposed to ovalbumin and treated with different TLR agonists as indicated in material and methods (Fig. 1C). (A) Whole lung lavage was collected $24 \mathrm{~h}$ after the last exposure and the number of inflammatory cells and (B) levels of IL-4 and IL-5 in the whole lung lavage were determined. Data are presented as mean \pm SEM of 8 mice/group. $* * p<0.01$, *** $p<0.001$, in 21 comparison with the ovalbumin group. 


\section{Figure 1}
A

Immunization
i.p. ovalbumin+Al(OH)
0
Challenge
$1 \%$ ovalbumin aerosol
$\downarrow$
$262728 \rightarrow$ Analysis
i.
i.tr. TLR-agonist
B

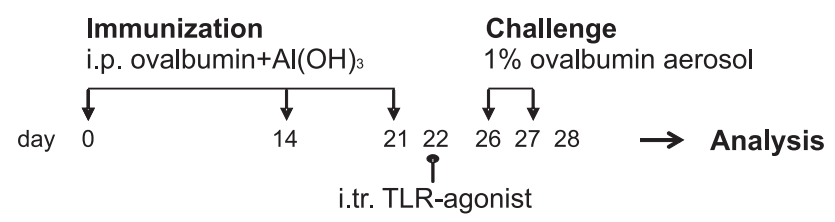
C

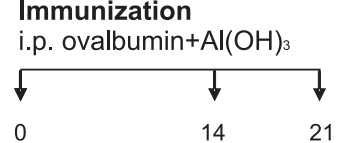


Figure 2

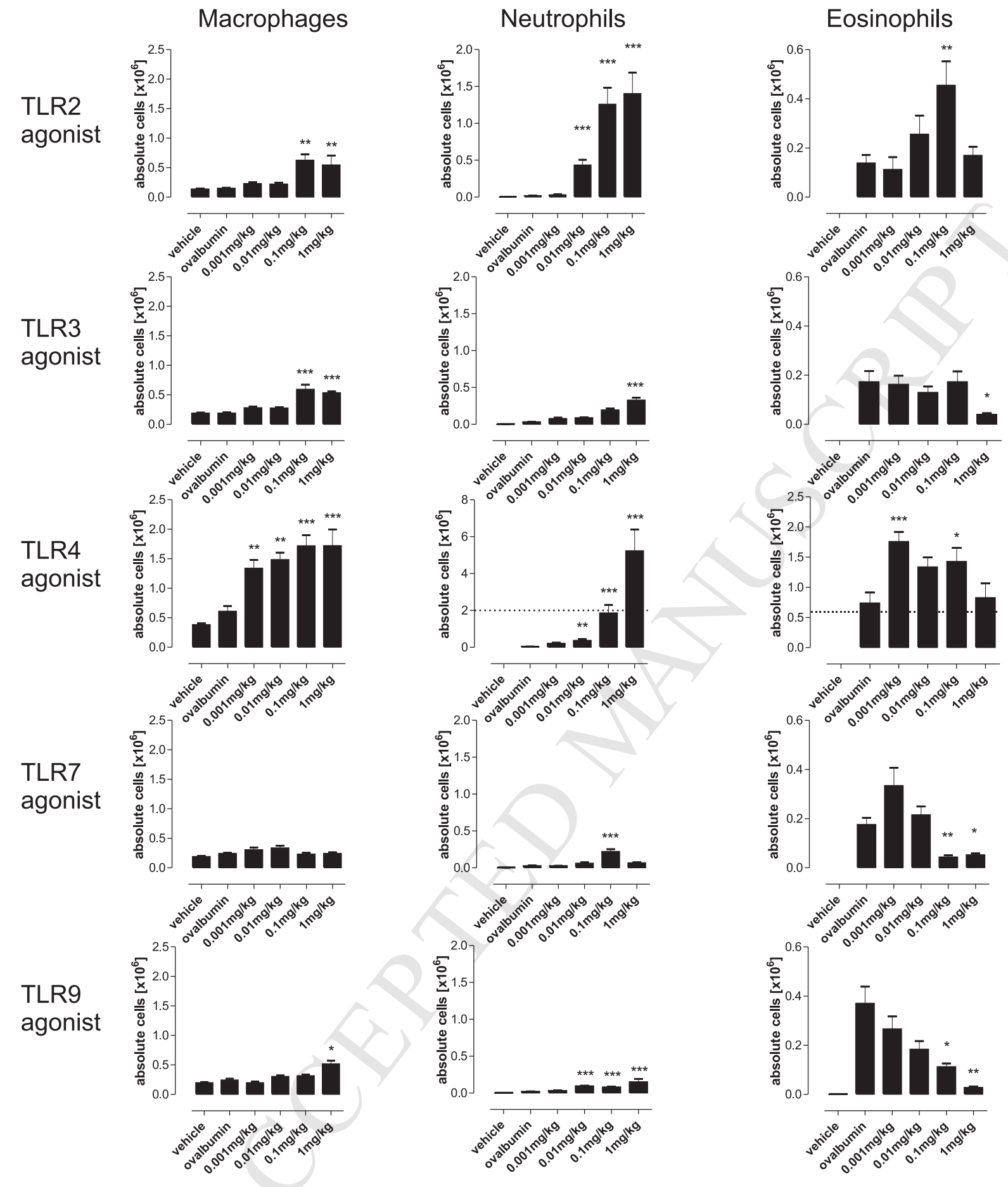


Figure 3

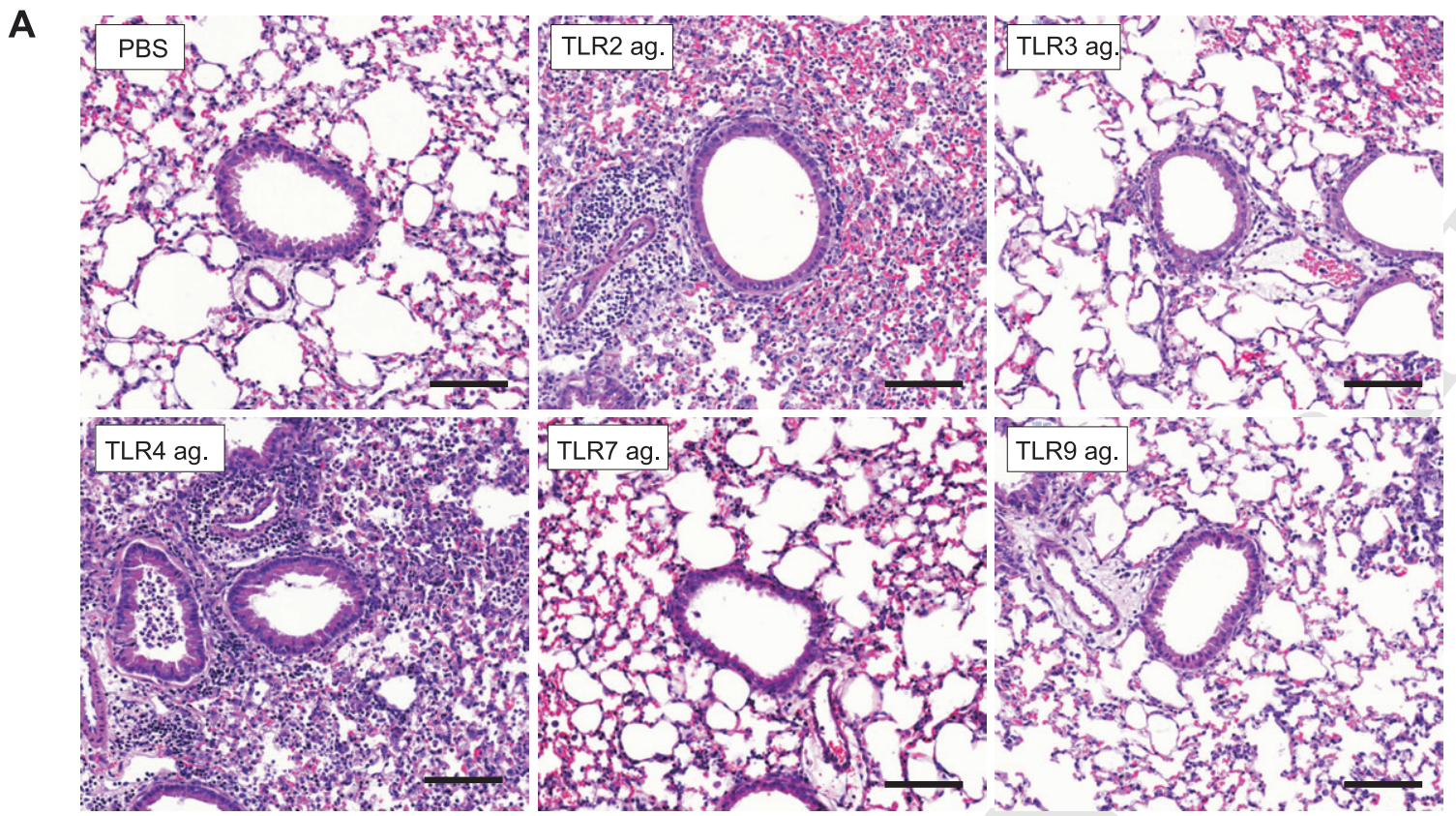

B
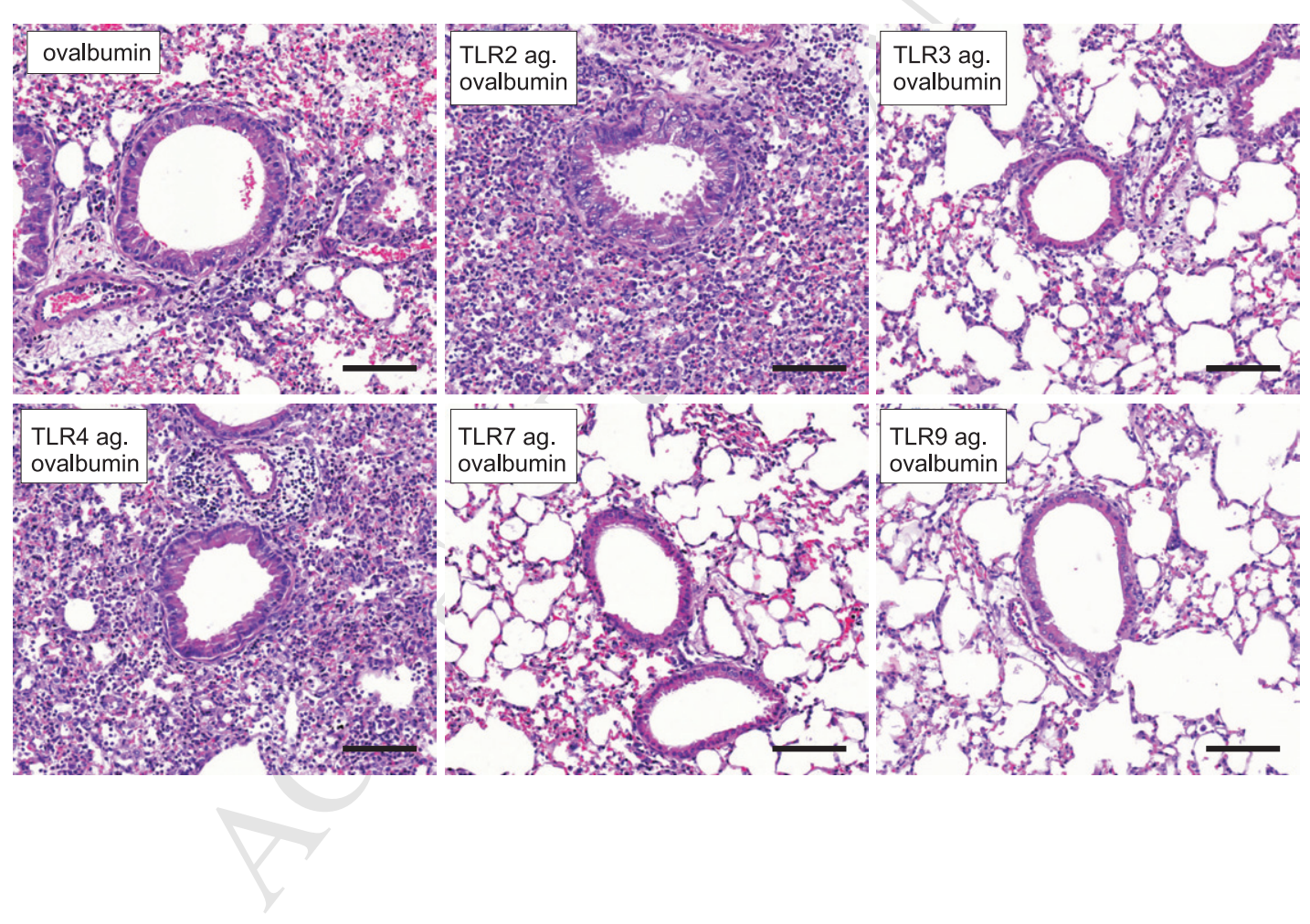
Figure 4
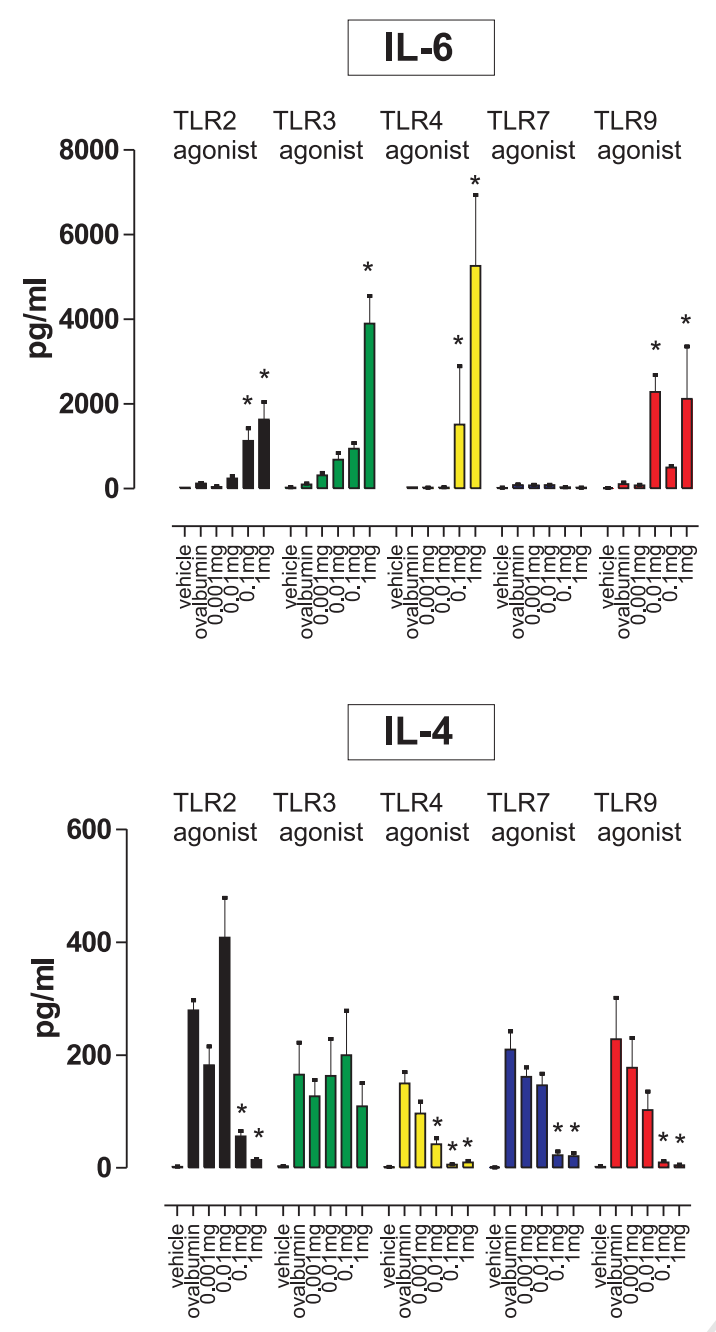

\section{IL-10}

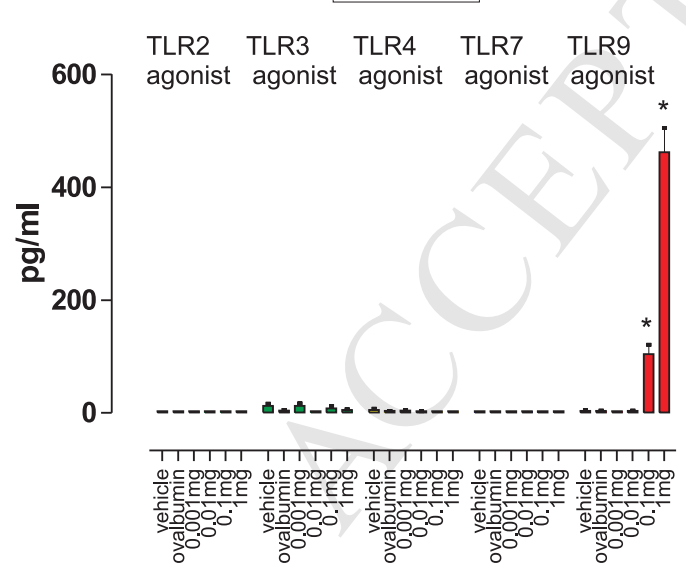

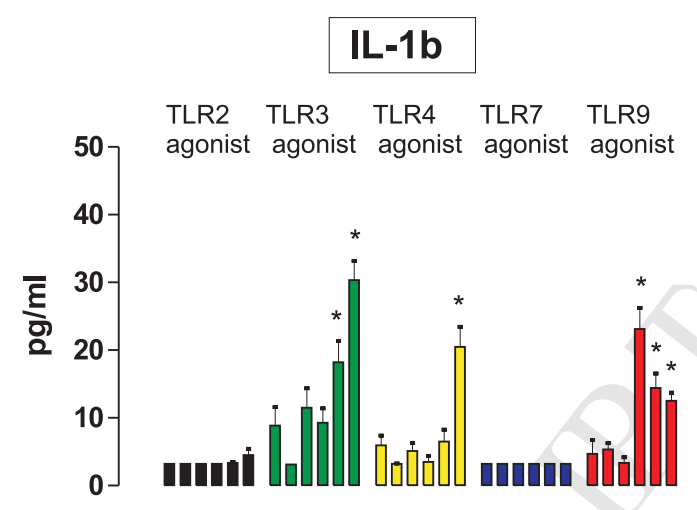

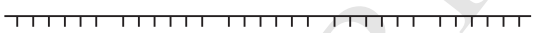

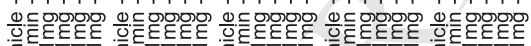

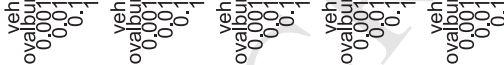
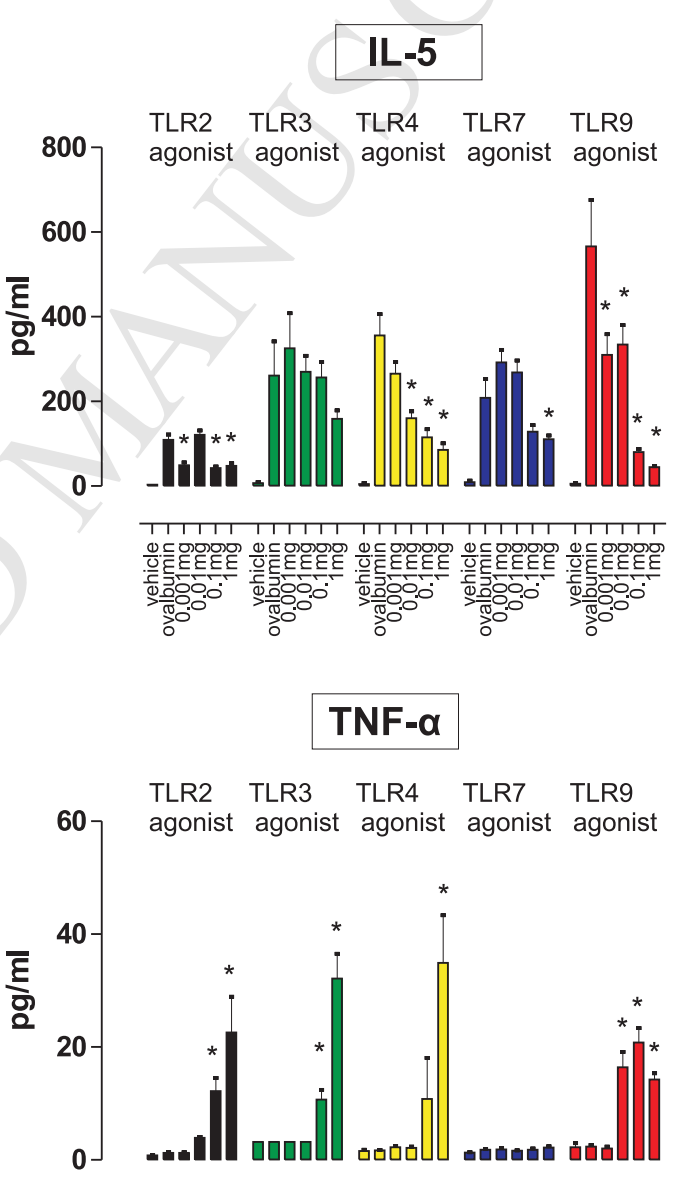

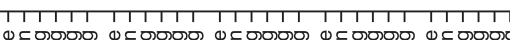

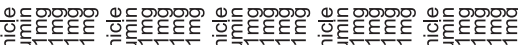

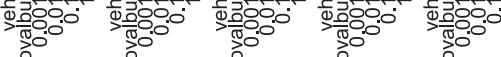


Figure 6

A

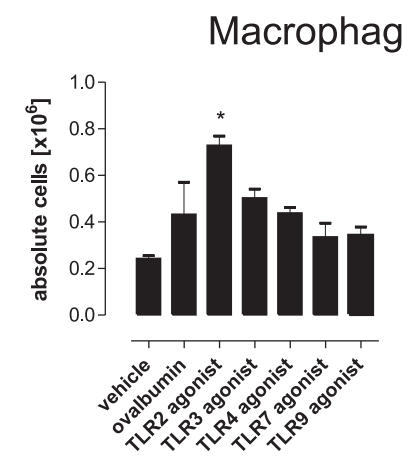

B

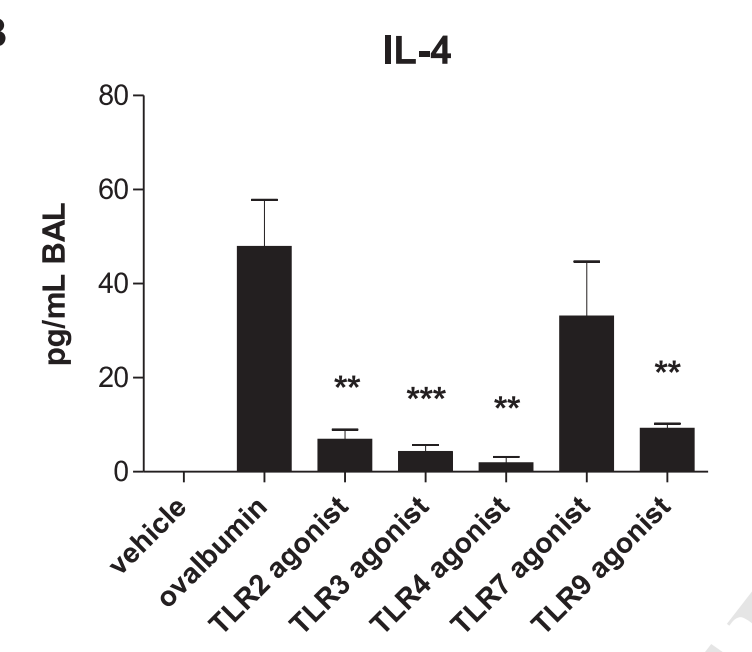

C

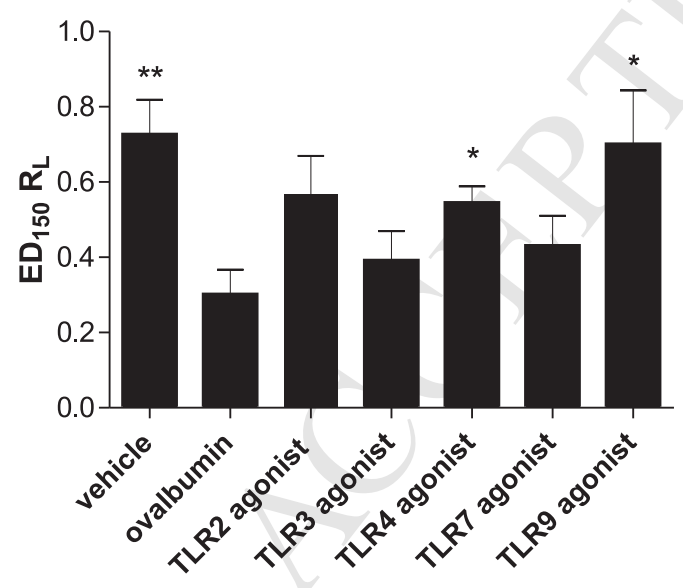

Neutrophils

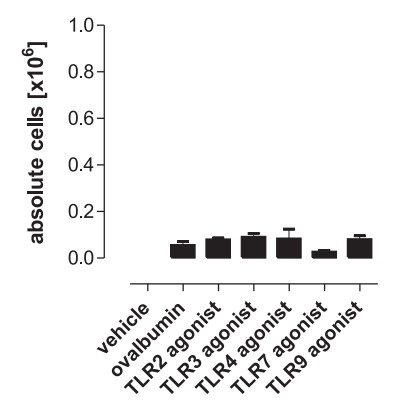

IL-5

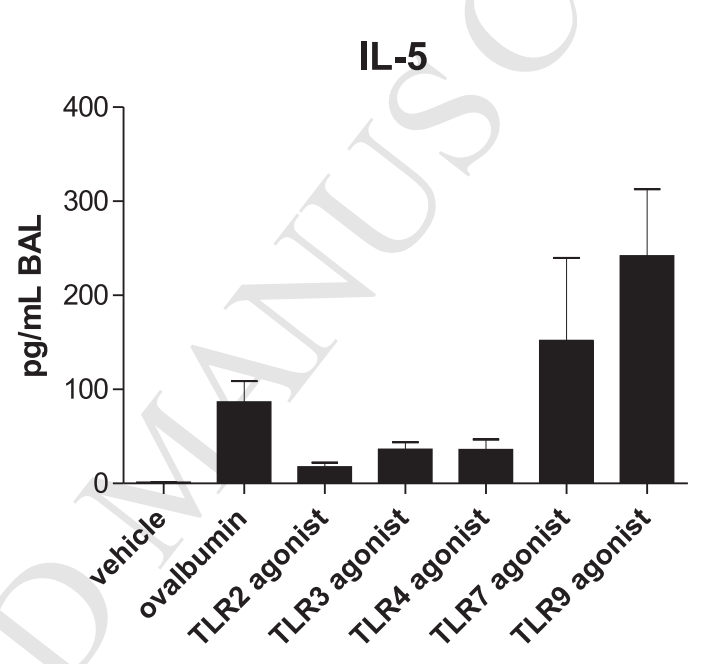

Eosinophils

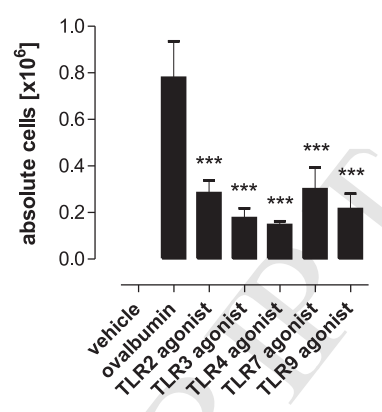


Figure 7

A
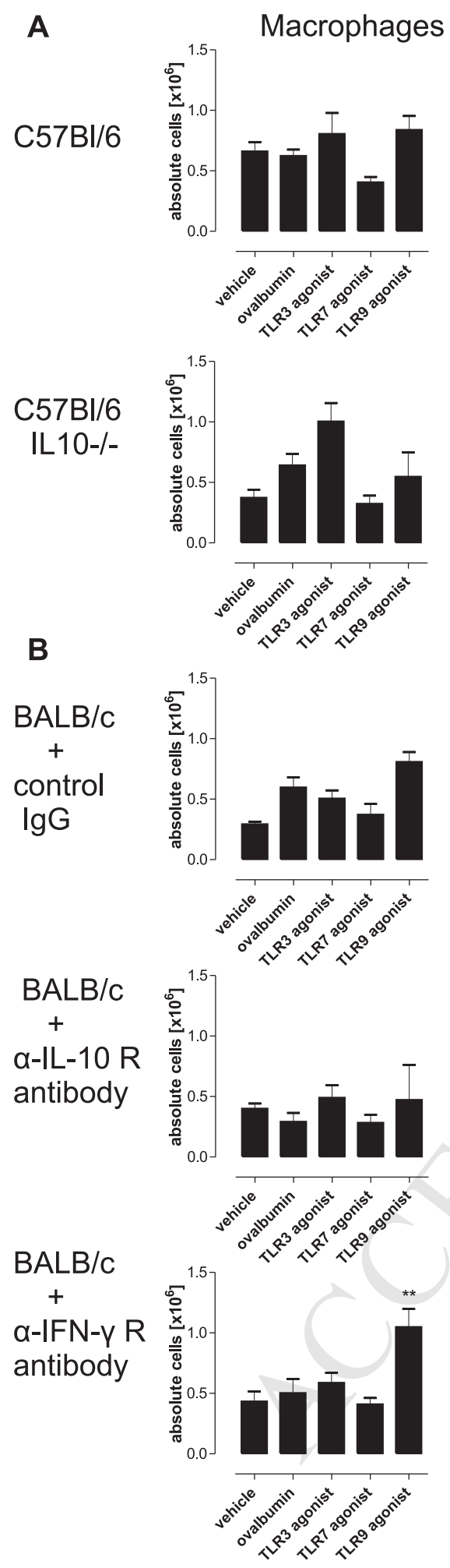

Neutrophils
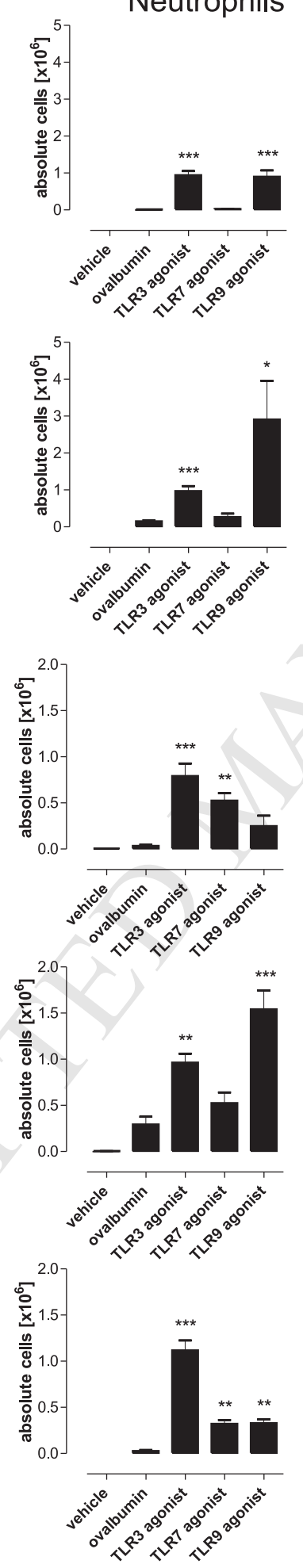

Eosinophils
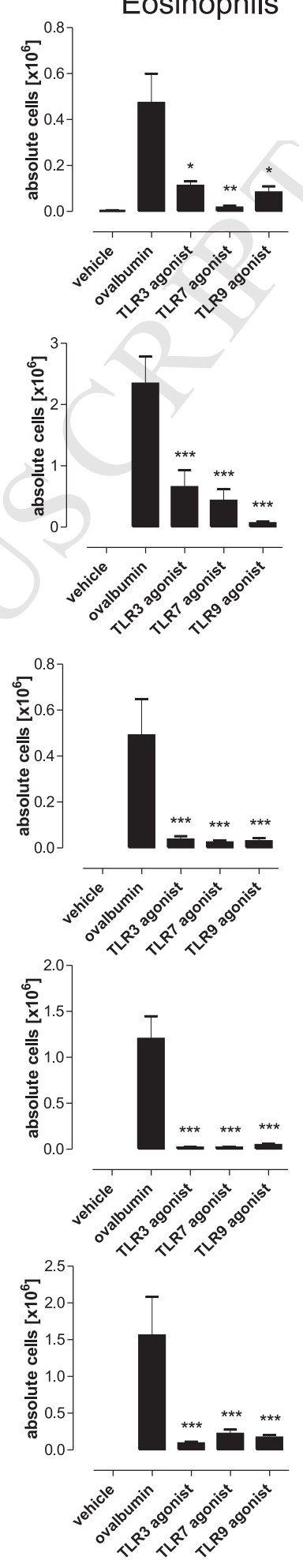
Figure 8

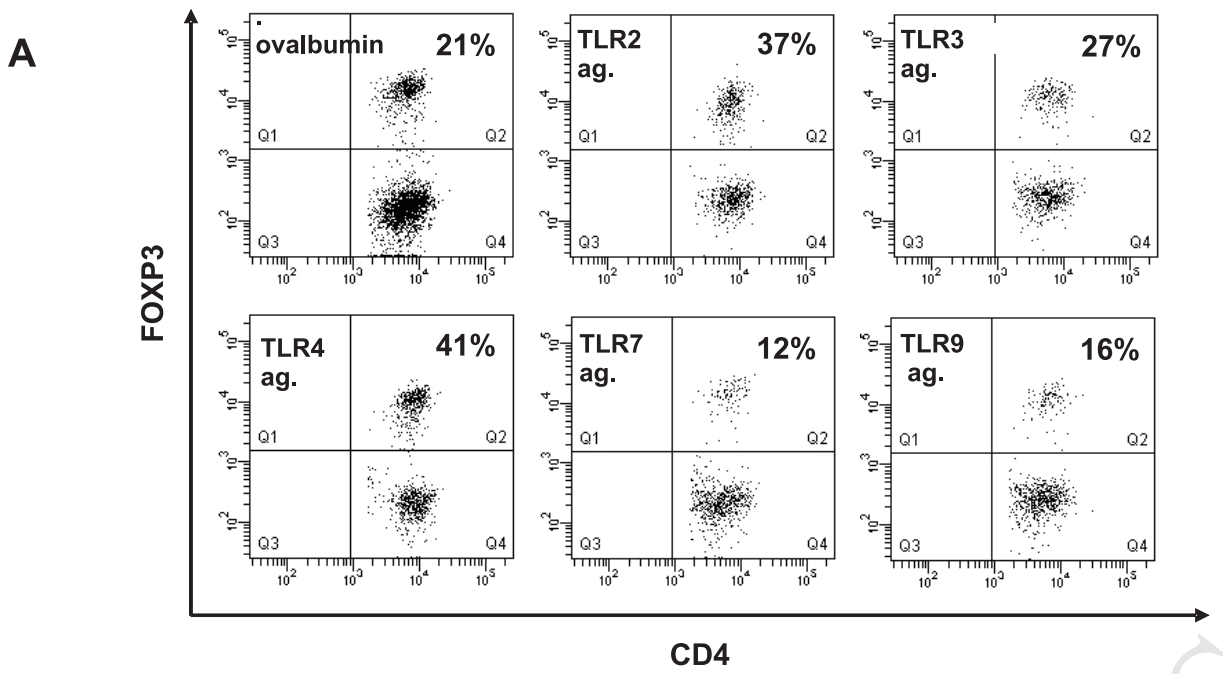

B

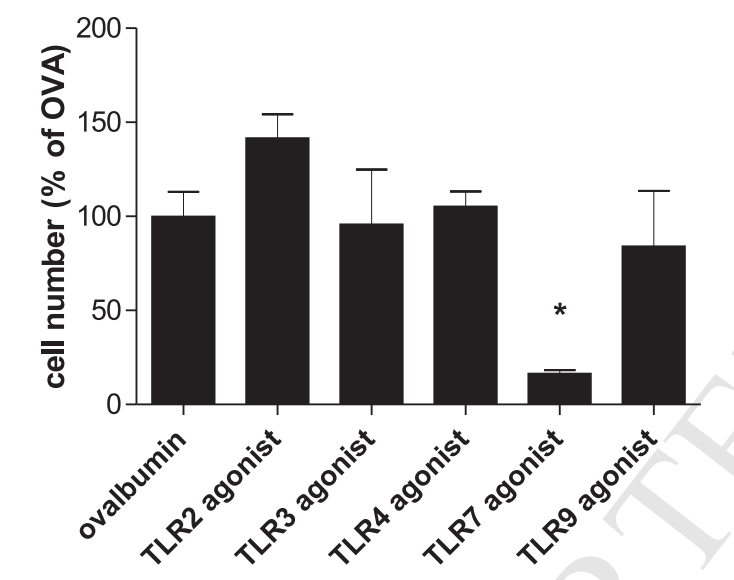

C

\section{FOXP3}

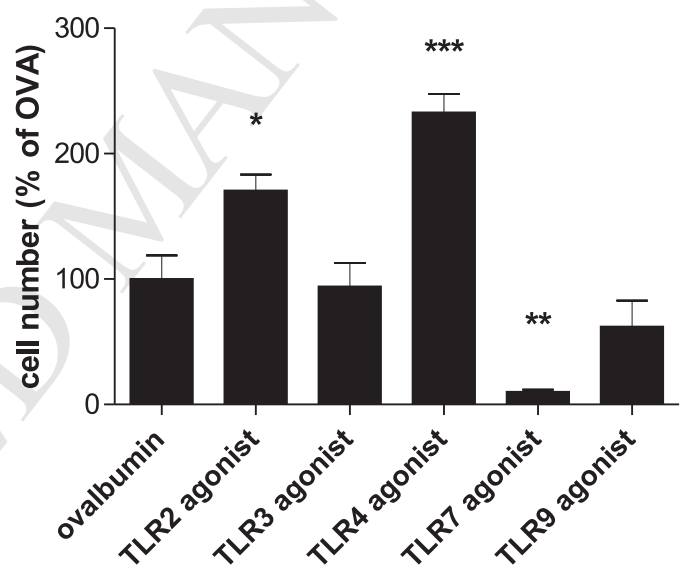


Figure 9

A

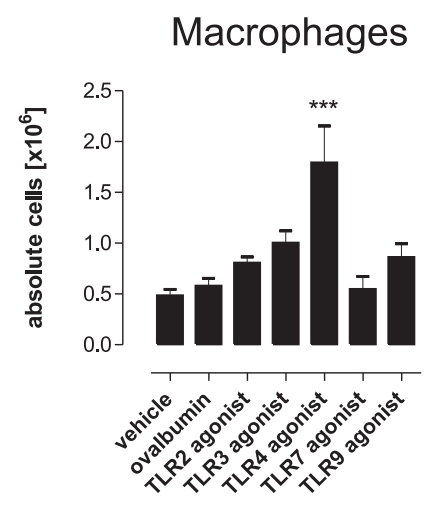

B

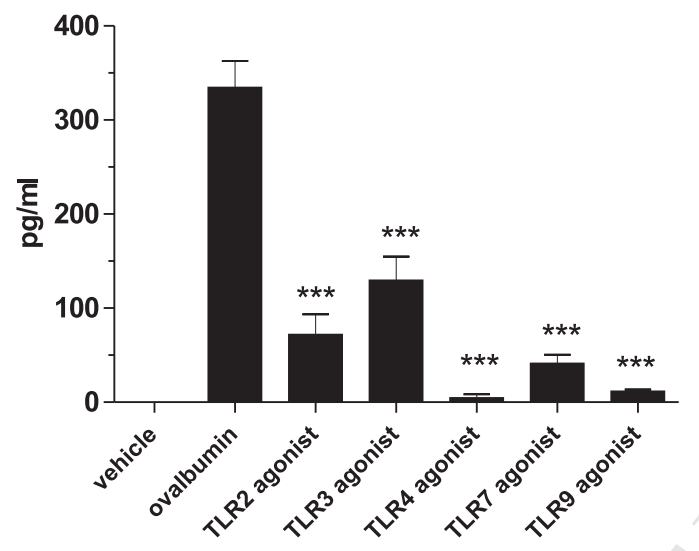

Neutrophils

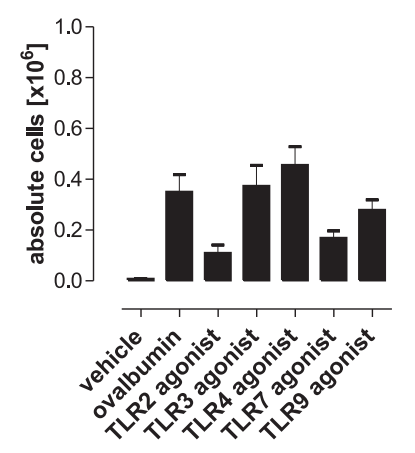

Eosinophils

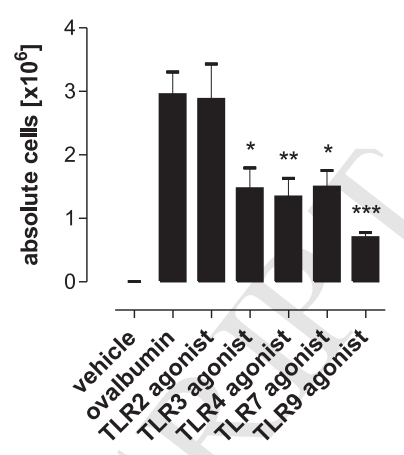

IL-5

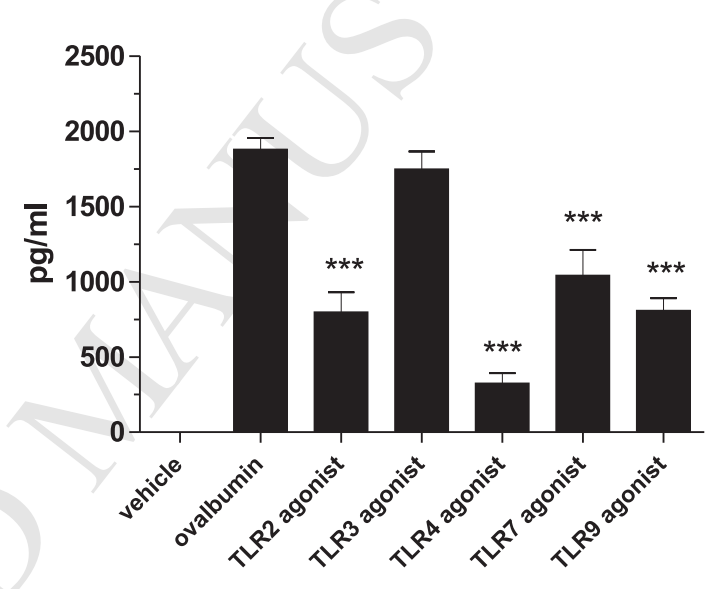

